\title{
Chloroquine for SARS-CoV-2: Implications of Its Unique Pharmacokinetic and Safety Properties
}

\author{
Cornelis Smit ${ }^{1,2}\left(\right.$ D $\cdot$ Mariska Y. M. Peeters ${ }^{3} \cdot$ John N. van den Anker ${ }^{1,4}\left(C_{0} \cdot\right.$ Catherijne A. J. Knibbe $^{2,3}(\mathbb{C}$
}

Published online: 18 April 2020

(c) The Author(s) 2020

\begin{abstract}
Since in vitro studies and a preliminary clinical report suggested the efficacy of chloroquine for COVID-19-associated pneumonia, there is increasing interest in this old antimalarial drug. In this article, we discuss the pharmacokinetics and safety of chloroquine that should be considered in light of use in SARS-CoV-2 infections. Chloroquine is well absorbed and distributes extensively resulting in a large volume of distribution with an apparent and terminal half-life of 1.6 days and 2 weeks, respectively. Chloroquine is metabolized by cytochrome P450 and renal clearance is responsible for one third of total clearance. The lack of reliable information on target concentrations or doses for COVID-19 implies that for both adults and children, doses that proved effective and safe in malaria should be considered, such as 'loading doses' in adults $(30 \mathrm{mg} / \mathrm{kg}$ over $48 \mathrm{~h}$ ) and children (70 mg/kg over 5 days), which reported good tolerability. Here, plasma concentrations were $<2.5 \mu \mathrm{mol} / \mathrm{L}$, which is associated with (minor) toxicity. While the influence of renal dysfunction, critical illness, or obesity seems small, in critically ill patients, reduced absorption may be anticipated. Clinical experience has shown that chloroquine has a narrow safety margin, as three times the adult therapeutic dosage for malaria can be lethal when given as a single dose. Although infrequent, poisoning in children is extremely dangerous where one to two tablets can potentially be fatal. In conclusion, the pharmacokinetic and safety properties of chloroquine suggest that chloroquine can be used safely for an acute virus infection, under corrected QT monitoring, but also that the safety margin is small, particularly in children.
\end{abstract}

\section{Introduction}

There is an increasing interest in chloroquine for the treatment of COVID-19-associated pneumonia since in vitro studies suggested the inhibition of SARS-CoV-2 [1,2], and Gao et al. issued a statement indicating the superiority of

Electronic supplementary material The online version of this article (https://doi.org/10.1007/s40262-020-00891-1) contains supplementary material, which is available to authorized users.

Catherijne A. J. Knibbe

c.knibbe@antoniusziekenhuis.nl

1 Pediatric Pharmacology and Pharmacometrics Research Center, University of Basel Children's Hospital, Basel, Switzerland

2 Department of Systems Biomedicine and Pharmacology, Leiden Academic Centre for Drug Research, Leiden University, Leiden, The Netherlands

3 Department of Clinical Pharmacy, St. Antonius Hospital, Koekoekslaan 1, 3435 CM Nieuwegein, The Netherlands

4 Division of Clinical Pharmacology, Children's National Hospital, Washington, DC, USA this almost 90-year-old drug compared with control treatment in more than 100 SARS-CoV-2-infected patients [3]. Introduced in the 1940s, as an antimalarial drug, chloroquine increases the $\mathrm{pH}$ of intracellular organelles such as endosomes and lysosomes essential for membrane fusion. It also appears to interfere with terminal glycosylation of the cellular receptor, angiotensin-converting enzyme 2 , which may influence the virus-receptor binding and enhance its antiviral properties [4].

In the past, the growth of different viruses, including SARS-CoV, was reported to be inhibited in cell cultures by chloroquine and hydroxychloroquine. However, despite extensive preclinical and clinical studies, no single acute virus infection has been successfully treated by chloroquine in humans, with even a bad long-term outcome reported in some clinical trials [5]. In light of the current SARS-CoV-2 pandemic, results of well-designed placebo-controlled clinical studies with chloroquine vs standard of care with relevant clinical endpoints are urgently needed. In the meantime, chloroquine has become one of the main therapeutics in treating COVID-19-associated pneumonia because of its availability, known safety record, and relatively low cost. 


\section{Key Points}

Although interest in the use of chloroquine for the treatment of COVID-19-associated pneumonia has recently increased because of in vitro efficacy studies and a preliminary clinical report, reliable information on chloroquine including doses or target concentrations for this application is lacking

Until information of high-quality studies becomes available, we suggest considering dose regimens that have proven to be effective and safe in other diseases, such as malaria, to guide chloroquine dosing in SARS-CoV-2 infections in adults and children

Given the unique pharmacokinetic profile of chloroquine and data from several pharmacokinetic studies, no large impact of renal dysfunction, critical illness, or obesity is expected, although in critically ill patients, drug absorption might be hampered

Although chloroquine seems well tolerated in therapeutic dose regimens under corrected QT monitoring, it has been shown to be possibly lethal in short-term intoxications, especially in children, for which caution is warranted

Awaiting further evidence of its potential use in the treatment of COVID-19-associated pneumonia, we discuss here the unique pharmacokinetic and safety properties of chloroquine retrieved from preclinical and clinical experience with this drug for malaria and other diseases. These should be considered when treating COVID-19-associated pneumonia with chloroquine, or when designing or interpreting results from clinical studies on the effects of chloroquine in these patients.

\section{General Pharmacokinetic Properties}

Oral absorption of chloroquine is nearly complete with an estimated bioavailability of $78 \%$ and $89 \%$ for the oral solution and tablet, respectively [6, 7]. When administered with food, the time to peak concentration is similar, but plasma concentrations and area under the curve are reported to be higher, even though the effect of food seems to be subject to large inter-individual variability [8]. Magnesium-containing antacids can lower the absorption of chloroquine [9].

After absorption, chloroquine extensively distributes across all tissues resulting in a very large volume of distribution of $200 \mathrm{~L} / \mathrm{kg}$ which, combined with a slow elimination, results in a terminal half-life reported to vary between days and weeks depending on the sampling time used in the study $[7,10,11]$. The apparent half-life, however, is much shorter at 1.6 days [12]. Nonetheless, even after a single dose in humans, chloroquine can be measured in plasma and urine at weeks or even over a year after dosing as a result of redistribution from the tissue compartments [13]. Chloroquine is actively transported into the cell's lysosomes (or the malarial parasite's acidic food vacuole), where it is 'trapped' by protonation owing to the organelle's acidic environment [14]. Preclinical experiments show that, compared with plasma concentrations, concentrations in red blood cells are 7.3-10.4 times higher, in the heart 6.8-184 times higher, and in lung tissue 11.8-450 times higher when measured over a period of $168 \mathrm{~h}$ after a single dose [15]. The variation in these factors within the same tissue is explained by a slower decrease in tissue concentrations compared with plasma, leading to the highest differences at the latest time point (i.e., $168 \mathrm{~h}$ ) after this single dose. Similarly, concentrations in whole blood are reported to be between 2.5, 3.7, or even 8 times higher compared with plasma concentrations [1, 16, 17], which should be considered when comparing results of different clinical reports with some studies reporting chloroquine concentrations in whole blood [18] or dried blood spot samples [19], while other studies report plasma concentrations [20]. Furthermore, concentrations measured in serum have been reported to be higher than those measured in plasma because platelet-bound chloroquine may release during clot formation [21]. Protein binding of chloroquine is irrelevant [22].

Chloroquine pharmacokinetics are linear when dosed between 2 and $15 \mathrm{mg} / \mathrm{kg}$ [23] and it is metabolized extensively by $\mathrm{N}$-dealkylation in the liver, catalyzed by several members of the cytochrome P450 (CYP) family, to desethylchloroquine and bisdesethylchloroquine. Desethylchloroquine is considered an active metabolite against Plasmodium falciparum, albeit less effective than chloroquine [14], and was, similar to chloroquine, reported to be active against the Zika virus [24]. However, no data are available on the effectiveness of desethylchloroquine in SARS-CoV-2. Bisdesethylchloroquine is reported to be a toxic metabolite associated with heart failure due to long-term treatment with chloroquine [25]. Involved CYPs, based on human liver microsome studies, include CYP1A2, CYP2C8, CYP2C19, CYP2D6, and CYP3A4/5 with CYP2C8 and CYP3A4/5 as major enzymes responsible for the formation of desethylchloroquine [26]. Although pharmacokinetic interactions can hence be expected in combination with CYP-inhibiting drugs [9], chloroquine is more infamous for its role as a perpetrator drug in several interactions. For example, higher concentrations of cyclosporine $[27,28]$ and potentially of $P$-glycoprotein substrates such as digoxin [9], dabigatran, or edoxaban have been described, even though digoxin and chloroquine were combined successfully in a case of 
myocarditis as a result of malaria infection [29]. Renal clearance was found to constitute $57 \%$ of total body clearance after a single dose [7] vs $33 \%$ in steady state [30]. In total, $55 \%$ of the dose is recovered in urine of which chloroquine constitutes $70 \%$ of the total amount recovered, resulting in an unchanged elimination of chloroquine of 38\% [30]. Given the extreme affinity of chloroquine for tissues, redistribution from the periphery to the blood compartment is the ratelimiting step for elimination of the drug from the human body [7].

Chloroquine is clinically administered as a racemic mixture, with similar pharmacodynamic properties, but slightly differrent pharmacokinetics between both enantiomeres being reported, the latter mostly regarding protein binding and clearance [31]. As the clinical implications are not well established to date, and most (pharmacokinetic) studies report total concentrations of chloroquine only (i.e., the sum of both enantiomers), we focus on the total chloroquine concentration in this article.

\section{Safety Aspects to Consider in Acute Viral Infections}

For the use of chloroquine in an acute viral infection such as COVID-19-associated pneumonia, early achievement of 'target' concentrations at the site of action seems a prerequisite for its potential efficacy but also poses a safety risk. More specifically, to achieve these concentrations early after the start of treatment, for this drug with extensive distribution and slow elimination, high loading dosages are required. Hence, information on the safety of these high dosages is paramount.

It is known from reports on chloroquine overdose that it can cause severe life-threatening toxicity, with ingestion of a dose of $5 \mathrm{~g}$ in adults being almost universally lethal when untreated [32]. Moreover, among persons ingesting $2.25 \mathrm{~g}$ or more, corresponding to only three times a therapeutic dose of $10 \mathrm{mg} / \mathrm{kg}$ for a typical adult patient, an overall mortality rate of 19\% was reported [33]. Acute toxicity in overdose occurs very rapidly with gastrointestinal and neurological symptoms within the first hour, rapidly followed by impaired ventricular conduction, wide QRS complexes $>100 \mathrm{~ms}$, corrected QT (QTc) prolongation, hypotension, and severe hypokalemia secondary to intracellular potassium shifting, resulting in an increased risk of ventricular dysrhythmias (i.e., torsades de pointes). Aggressive treatment consisting of a combination of early mechanical ventilation, administration of diazepam and epinephrine together with potassium correction may be effective, also in cases with chloroquine doses above $5 \mathrm{~g}$ [32]. This treatment protocol was even successful in a massive overdose where a plasma concentration of $47 \mu \mathrm{mol} / \mathrm{L}$ was measured [34]. In this case, treatment could be gradually discontinued on the third day with extubation $66 \mathrm{~h}$ after admission at which time the plasma chloroquine concentration was $2.4 \mu \mathrm{mol} / \mathrm{L}$ [34]. These cases illustrate that toxic effects rarely last more than $24 \mathrm{~h}$, despite a terminal elimination half-life of 14 days. This can be explained by the short apparent half-life of 1.6 days due to rapid distribution of chloroquine from the central compartment with extensive tissue binding.

Over the years, several (whole blood) chloroquine concentrations have been proposed as a cut-off point for toxicity in acute intoxications. A fatal outcome was reported above whole blood concentrations of $25 \mu \mathrm{mol} / \mathrm{L}$ [32, 34]. However, others refer to Stead and Moffat who reported fatal or toxic whole blood concentrations of 7 and $2.3 \mu \mathrm{mol} / \mathrm{L}$, respectively [35], or to Jaeger et al. who report serum concentrations of 7.8 and $15.5 \mu \mathrm{mol} / \mathrm{L}$ for moderate and severe intoxications [36]. As it is particularly difficult in a short-term dosage to make direct comparisons between blood, serum, and plasma concentrations with reported correction factors between whole blood and plasma varying between 2.5 and 8 $[1,16,17]$, it seems that these concentrations can currently not be used as a guide [34]. Perhaps the earlier mentioned plasma concentration of $2.4 \mu \mathrm{mol} / \mathrm{L}$, measured around extubation in a patient $66 \mathrm{~h}$ after a massive overdose could be considered as a boundary for (minor) toxicity [34]. A similar threshold was found with long-term use of chloroquine in rheumatoid arthritis, where in $80 \%$ of patients with serum concentrations above $0.8 \mu \mathrm{g} / \mathrm{mL}$ (or $2.5 \mu \mathrm{mol} / \mathrm{L}$ ) side effects such as visual and central nervous system disturbances were reported, whereas when concentrations were lower than 0.4 $\mu \mathrm{g} / \mathrm{mL}$ (or $1.3 \mu \mathrm{mol} / \mathrm{L}$ ), there were no side effects. Except for maculopathy in one patient, all side effects reversed on discontinuation of the drug [37]. Furthermore, after intravenous administration of a 300-mg dose, side effects such as difficulties with swallowing, fatigue and ocular side effects such as diplopia or problems with accommodation occurred within the first 45 min of dosing, when peak plasma concentrations of $837 \mathrm{ng} / \mathrm{mL}$ (corresponding to $2.61 \mu \mathrm{mol} / \mathrm{L}$ ) were reached [7]. No adverse reactions were observed after oral doses of $300 \mathrm{mg}$, yielding median peak concentrations of $73 \mathrm{ng} / \mathrm{mL}$ (corresponding to $0.23 \mu \mathrm{mol} / \mathrm{L}$ ). Another study reported hypotension as a main adverse effect after parenteral chloroquine [6], which did not occur when chloroquine was administered over $1 \mathrm{~h}$. From these observations, it seems that during this initial phase after intravenous administration, chloroquine needs to be distributed from the relatively small central blood compartment resulting in transient high concentrations and a risk for acute toxicity, which is only observed for a very short time because of rapid distribution into tissues.

Regarding toxicity in children, it is known from many reports that poisoning in children, although infrequent, is extremely dangerous because children are particularly 
sensitive to chloroquine toxicity [38]. With (accidental) overdose, most children become symptomatic within $30 \mathrm{~min}$ after ingestion and may die within the first $3 \mathrm{~h}$ even with aggressive treatment. Ingestion of only one tablet of $300 \mathrm{mg}$ was fatal for a 12-month-old infant with a chloroquine serum concentration of $4.4 \mathrm{mg} / \mathrm{L}(13.6 \mu \mathrm{mol} / \mathrm{L})$ [39]. A 13-yearold boy who took approximately $750 \mathrm{mg}$ of chloroquine developed ventricular fibrillation at a plasma concentration of only $4.2 \mu \mathrm{mol} / \mathrm{L}$ [40]. Another case report presented a 3 -year-old child who died after taking two 150-mg base tablets of chloroquine [41]. From these case reports, it seems that even though patients' serum concentrations and clinical findings correlate well with adult findings, the outcome differs greatly between adults and children. These pediatric cases further underscore that chloroquine should be kept away from children and patients unfamiliar with its use.

A pharmacokinetic model developed under therapeutic use of chloroquine such as the Zhao et al. model [20] cannot be used for the prediction of concentrations with overdose in adults or children (see Electronic Supplementary Material $[\mathrm{ESM}])$. This observation suggests that after overdose, redistribution of the very high concentrations in the central compartment to the tissue compartments is not similar to redistribution with tissue binding after therapeutic dosages. This might be explained by lysosomal trapping of chloroquine, which is an active process that is probably saturable in the setting of a massive overdose [14].

\section{Can We Define a Dose or Target Plasma Concentration of Chloroquine for Treating COVID-19-Associated Pneumonia?}

In vitro EC50 values for chloroquine in SARS-CoV-2 were reported between 1.13 [2] and $5.47 \mu \mathrm{M}$ [1]. For SARS-CoV, the IC50 value was $8.8 \mu \mathrm{M}$ with as little as $0.1-1 \mu \mathrm{M}$ of chloroquine reducing the infection by $50 \%$ and up to $90-94 \%$ inhibition with 33-100 $\mu \mathrm{M}$ concentrations [42]. In this respect, results of in vitro EC50 values are known to vary between cell types with the virus being able to adapt in cell culture [1]. Moreover, in vitro studies have not shown to be very predictive for the animal or human situation [5].

It is unknown how to relate in vitro values to the abovereported extreme differences in concentrations between red blood cells, plasma, and the presumed target tissue, like for instance the lung in pneumonia related to COVID-19. Given the extensive distribution to tissue, plasma concentrations may or may not be of predictive value as an efficacy measure. For most antibacterial drugs, concentrations in plasma correlate with unbound concentrations in the interstitial fluid and are therefore considered best predictors for efficacy [43]. However, this assumption has been challenged by others, promoting the direct measurement of the free fraction of antibiotics in the extracellular fluid directly via microdialysis [44]. Measuring drug concentrations in tissue homogenates is currently widely abandoned, as this approach does not take into account that tissues consist of multiple compartments over which the drug does not necessarily distribute equally $[44,45]$. Second, the ratio between plasma and tissue concentrations varies over time, making multiple measurements per individual necessary, which gives practical and ethical problems [45]. To our knowledge, only one study assessed the lung penetration of chloroquine, which was performed in rats by measuring tissue homogenate [15]. These data were recently incorporated in a COVID-19 physiologically based pharmacokinetic model by Yao et al. to simulate lung concentrations in relation to the EC50 values found in vitro [1]. In addition to the major drawbacks regarding concentrations in tissue homogenates, it also remains unclear what the particular site of action of chloroquine is in COVID-19-associated pneumonia. A parallel can be made to azithromycin, another basic drug that has been shown to accumulate in lung macrophages and, by being slowly released into extracellular fluid, was highly effective in eradicating Haemophilus influenzae from the lung in a mouse model [46]. However, it is unclear whether these principles also apply to chloroquine and its antiviral activity. Therefore, we argue that to date we do not have enough information yet to identify whether concentrations in lung tissue from homogenates or concentrations in extracellular fluid or in lysosomes would be the target for a chloroquine dose strategy for COVID-19-associated pneumonia. As such, until more knowledge is obtained on in vivo target exposures, we should focus on dosages that have shown to be safe in other diseases, such as malaria.

\section{What can We Learn from Chloroquine Studies Performed in Adults and Children with Malaria}

In view of the small differences between effective and toxic doses, it seems that for COVID-19-associated pneumonia, advantage should be taken of (safety) experience obtained for the treatment of malaria where high loading doses are given over 1-3 days in adults and children. In these studies, it has been shown that higher initial doses at the start of treatment may be beneficial and are safe. In a clinical study by Pussard et al., a high dose $(30 \mathrm{mg} / \mathrm{kg}$ over 2 days: $10 \mathrm{mg} /$ $\mathrm{kg}$ at $0 \mathrm{~h}, 5 \mathrm{mg} / \mathrm{kg}$ at $6 \mathrm{~h}, 12 \mathrm{~h}, 24 \mathrm{~h}$, and $36 \mathrm{~h}$ ) was reported to result in a reduced time required for a $50 \%$ decrease in the initial parasitemia $(14.3 \pm 1.6 \mathrm{~h}$ vs $35.5 \pm 5.4 \mathrm{~h}, p<0.01)$ and more rapidly obtained negative blood smears $(50.8 \pm 3.7$ vs $72 \pm 8.7 \mathrm{~h})$ compared with a standard dose $(25 \mathrm{mg} / \mathrm{kg}$ over 3 days: $10 \mathrm{mg} / \mathrm{kg}$ at $0 \mathrm{~h}, 24 \mathrm{~h}$, and $5 \mathrm{mg} / \mathrm{kg}$ at $48 \mathrm{~h}$ ) [47]. As Pussard et al. [47] reported that this 'loading dose' of $30 \mathrm{mg} /$ 
$\mathrm{kg}$ given over $48 \mathrm{~h}$ was well tolerated, this seems a dosing regimen that deserves attention when studying the effects of chloroquine in SARS-CoV-2. Using this regimen, higher concentrations earlier in treatment may be obtained compared to other proposed dosages for SARS-CoV-2. Figure 1 shows concentration-time profiles that can be expected in a standard individual of $70 \mathrm{~kg}$ with this high loading dose over $48 \mathrm{~h}$ according to Pussard et al. [47] (panel B) compared to one of the currently proposed dosages for COVID19-associated pneumonia (panel A), which is a fixed dose of $3300 \mathrm{mg}$ over 5 days with $600 \mathrm{mg}$ and $300 \mathrm{mg}$ on the first day (see ESM for details). To generate these plots, the pharmacokinetic model published by Zhao et al. [20] was used after it had been extensively evaluated for its predictive performance with observations from a large number of other pharmacokinetic studies including studies in children (from 0.5 to 18 years of age) and adults with renal dysfunction [10, 18, 19, 47-52] (see ESM for details about the model and simulations). In this figure, it can be seen that the high loading dose schedule of Pussard et al. [47] may lead to higher chloroquine plasma concentrations at the beginning of therapy without increasing the maximum concentration compared to the standard dose for individuals of $70 \mathrm{~kg}$ without renal dysfunction.

Similarly, in 4- to 8-year-old children with malaria, highdose chloroquine ( 50 or $70 \mathrm{mg} / \mathrm{kg}$ over 3 or 5 days) resulted in higher early chloroquine concentrations compared with standard treatment with $25 \mathrm{mg} / \mathrm{kg}$ in a study by Ursing et al. [19]. Malaria symptoms were reported to resolve by day 3 in parallel with increasing chloroquine concentrations. Both dosages of 50 and $70 \mathrm{mg} / \mathrm{kg}$ over 3-5 days were well tolerated. While there were no significant changes in blood pressure or heart rate, the median QTc interval was 12-26 ms higher at expected peak concentrations than at day $0(p<0.001)$, which is similar to changes reported in adults. Other side effects included vomiting and one case of convulsions, which were most probably the result of malaria and not due to chloroquine toxicity [19]. More experience on the $50-\mathrm{mg} / \mathrm{kg}$ dose over 3 days in children varying in age between 6 months and 15 years of age is available in other studies from the same author [53]. Similarly, Zhao et al. reported that children under the age of 5 years may require a higher milligram/kilogram dose than adults to achieve the same chloroquine exposure [20]. In Fig. 2,

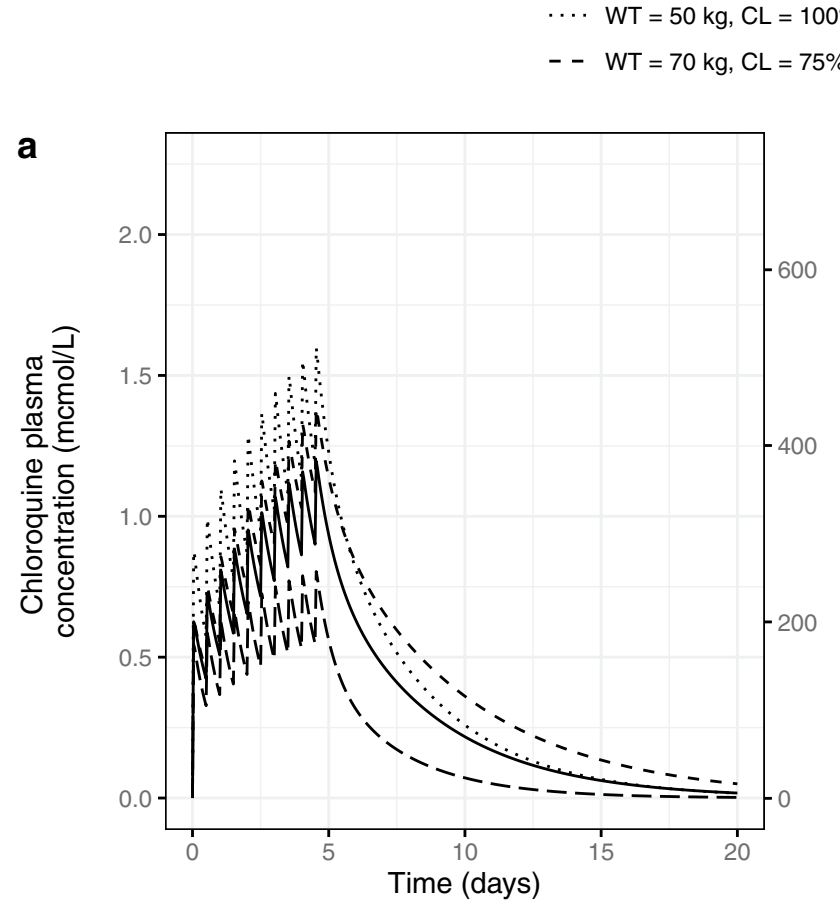

Fig. 1 Plasma concentration-time profile in a typical adult patient of $50 \mathrm{~kg}$ with normal renal function (dotted line), $70 \mathrm{~kg}$ with renal impairment (25\% reduction in clearance [CL], short dashed line), $70 \mathrm{~kg}$ with normal renal function (solid line), and in an obese adult of $150 \mathrm{~kg}$ with normal renal function (long dashed line) based on the pharmacokinetic model from Zhao et al. [20], which was adapted for obese patients (i.e., 0.75 allometric increase in $\mathrm{CL}$ and maximized volumes and intercompartmental $\mathrm{CL}$ on values for an $80 \mathrm{-kg}$ individual; see ESM for details). Two dose regimens were simulated: a

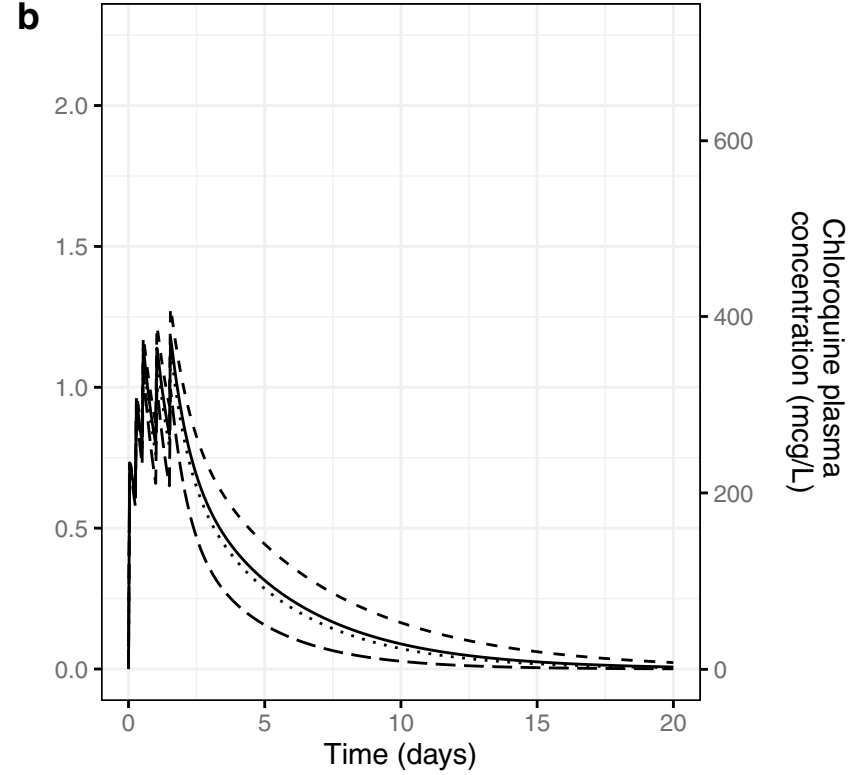

dose regimen according to the SWAB (Dutch Working Party on Antibiotic Policy) guideline [69] (total $3300 \mathrm{mg}$ over 5 days with 600 and $300 \mathrm{mg}$ on the first day) and $\mathbf{b}$ dose regimen according to Pussard et al. [47] (30 mg/kg over $48 \mathrm{~h}$ with a maximum dose of $2400 \mathrm{mg}$ [80 kg] for obese patients). Chloroquine concentrations are shown in $\mu \mathrm{mol} / \mathrm{L}$ (left axis) and $\mathrm{mcg} / \mathrm{L}$ (right axis). To compare plasma concentrations with whole blood concentrations, multiply by a factor of $2.5-8[1,16,17]$. WT body weight 
concentration-time profiles are shown for the currently proposed dose regimen for COVID-19-associated pneumonia in children, $55 \mathrm{mg} / \mathrm{kg}$ over 5 days (A) vs the $70-\mathrm{mg} / \mathrm{kg}$ dose over 5 days derived from Ursing et al. [19] (B) for children varying in age between 0.5 and 8 years of age based on the model published by Zhao et al. [20]. For children, this model was slightly adapted based on the predictive performance of the model against other reports in infants and children [19, $48,50,51]$, for which a reduced clearance with $25 \%$ and $50 \%$ was inserted in children below 5 and 1 year of age, respectively, on top of the allometric scaling that is already part of this model (see ESM). Comparable to what was seen in adults (Fig. 1), these concentration-time profiles show that the intense dose schedule proposed by Ursing et al. results in higher concentrations shortly after the start of therapy (panel B), while maximum concentrations remain similar compared to currently proposed dosages (panel A). Despite the fact that infants of 6 months of age were included in the original study by Ursing et al. [53], it seems that in this group higher concentrations are obtained with this dosing schedule compared with older children (Fig. 2b).

\section{Special Patient Populations}

In addition to how to dose chloroquine safely in children, as was discussed in the previous section, it is also important to know how to dose chloroquine in other special patient populations such as those with renal insufficiency, critical illness, and obesity, and whether race might have an impact. Acute renal insufficiency may occur as a result of multi-organ failure associated with severe acute SARSCoV-2 infection. Therefore, it is important to consider the influence of renal insufficiency when using chloroquine in COVID-19. Given the prolonged half-life that was reported in patients with chronic kidney disease [49], a longer time to steady state and higher steady-state concentrations can be expected in renal insufficiency when starting the treatment in the acute situation. In a study in six patients with chronic renal failure with plasma creatinine values varying between 1.6 and $12.7 \mathrm{mg} / \mathrm{dL}$ (or CKD-EPI between 5.3 and $68 \mathrm{~mL} /$ $\mathrm{min} / 1.73 \mathrm{~m}^{2}$ ), peak concentrations were as expected, while the elimination plasma half-life was prolonged. Evaluation of this data using the Zhao et al. model [20] showed that for most patients with renal impairment a reduction in clearance of $25 \%$ leads to a good description of the observed
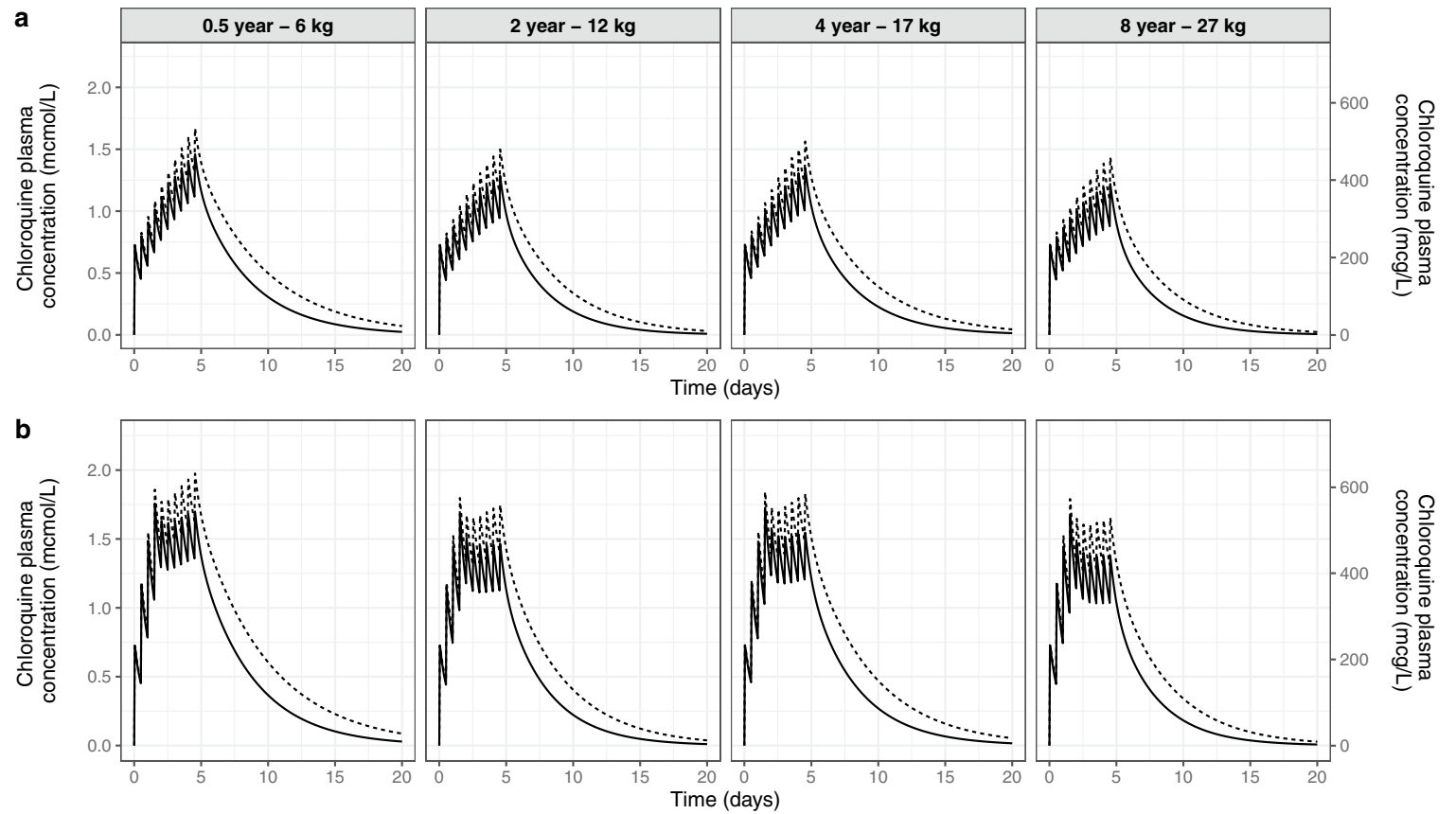

- $\mathrm{CL}=100 \%$

-... $\mathrm{CL}=75 \%$

Fig. 2 Plasma concentration-time profile in four typical children of $0.5,2,4$, and 8 years of age with normal renal function (solid line) or with renal impairment ( $25 \%$ reduction in clearance [CL], dashed line) based on the pharmacokinetic model from Zhao et al. [20], which was adapted for children aged below 5 and 1 years to be in agreement with observations in children in other reports $[19,50,51]$ (i.e., a reduction in CL to $75 \%$ and $50 \%$ on top of allometric scaling (that is already in the model) for children below 5 and 1 year of age, respec- tively (see ESM for details). Two dose regimens were simulated: a dose regimen according to the SWAB (Dutch Working Party on Antibiotic Policy) guideline/Dutch Children's Formulary [69] (total $55 \mathrm{mg} / \mathrm{kg}$ over 5 days) and $\mathbf{b}$ dose regimen according to Ursing et al. [19] (70 mg/kg over 5 days). Chloroquine concentrations are shown in $\mu \mathrm{mol} / \mathrm{L}$ (left axis) and $\mu \mathrm{g} / \mathrm{L}$ (right axis). To compare plasma concentrations with whole blood concentrations, multiply by a factor of 2.5-8 [1, 16, 17] 
concentrations (see ESM). This finding seems in line with the fact that chloroquine is extensively distributed and for the most part metabolized, with renal clearance of the parent compound being only about one third of total clearance [7, $30]$. We believe that this $25 \%$ reduction in clearance is also applicable to patients with a more severe renal dysfunction (under $10 \mathrm{~mL} / \mathrm{min} / 1.73 \mathrm{~m}^{2}$ ) because the potential further reduction in chloroquine clearance due to severe renal insufficiency may be compensated by renal replacement therapy. In a study in four adults undergoing hemodialysis, chloroquine was dialyzed with a clearance of $58 \mathrm{~mL} / \mathrm{min}$, which is around $15 \%$ of the normal total body clearance [54]. In Fig. 1, concentration-time profiles in adult patients with renal insufficiency are shown for the two different dosing regimens, illustrating a limited influence of renal dysfunction on plasma concentrations. The inclusion in this figure of an (underweight) individual of $50 \mathrm{~kg}$ with normal renal function shows that underweight leads to slightly higher concentrations when using a fixed-dose regimen (Fig. 1a), compared with an individual of $70 \mathrm{~kg}$ with renal dysfunction. The use of the loading dose scheme of Pussard et al. [47] reduces the differences between individuals with and without renal dysfunction or underweight (Fig. 1b). This demonstrates that the changes in chloroquine concentrations observed in patients with renal impairment are in the same order of magnitude as observed in a 50-kg patient with normal renal function (Fig. 1a). Additionally, in Fig. 2, the influence of renal dysfunction in children is illustrated compared to children with normal renal function. This figure underlines the limited impact of renal impairment when the currently used loading dose schemes are used.

Critical illness has been widely recognized as a disease state that can have major impact on drug pharmacokinetics [55]. Besides renal insufficiency, pro-inflammatory cytokines such as interleukin-6 or tumor necrosis factor have also been shown to influence drug clearance during systemic inflammatory response by, for example, suppression of CYP3A4 [55, 56]. As extreme inflammation has also been reported in critically ill COVID-19 patients, an important question is what to expect with regard to chloroquine pharmacokinetics in these patients. In a pharmacokinetic study by Edwards et al. in nine patients with malaria, a disease that is also characterized by high levels of pro-inflammatory cytokines [57], and ten healthy volunteers, no significant differences in chloroquine clearance were found [52]. Moreover, the evaluation of the Zhao et al. model, which was developed in healthy adult volunteers against data from patients with malaria, showed that this model could also predict the chloroquine plasma concentrations in patients with malaria over the first 10 days after an intravenous dose (see ESM for details). Potentially, this low influence of inflammation can be explained by the fact that chloroquine is extensively metabolized by a wide variety of CYP enzymes and for a part cleared renally. Moreover, this paper discussed chloroquine dose regimens of Pussard et al. [47] and Ursing et al. [19] with regard to safety and efficacy in malaria. Hence, it seems that no major differences in pharmacokinetics in critically ill COVID-19 patients are to be expected, even though pharmacokinetic studies evaluating this influence are awaited. When studying the pharmacokinetics in critically ill patients, one should remain aware of the fact that provided oral chloroquine is studied, clearance and volume of distribution over bioavailability (apparent clearance $[\mathrm{CL} / \mathrm{F}]$ or apparent volume of distribution [Vd/F]) are obtained with a potential influence of critical illness on clearance (or volume of distribution) or bioavaibility or both. Given the report that food may increase absorption [8], beside a (small) difference in clearance or volume of distribution, a difference in $\mathrm{F}$ may also be anticipated.

Regarding obese patients, doses may or may not require adaptation in this special population. As a general rule, this cannot be predicted on the basis of lipophilicity or elimination pathway alone $[58,59]$. Based on the first epidemiological studies on the SARS-CoV-2 virus, it appears that co-morbidities such as diabetes mellitus and hypertension increase the risk for development of acute respiratory distress syndrome [60]. Additionally, obesity has been described as an independent risk factor for hospitalization in respiratory viral infections, including coronaviruses [61]. Therefore, it can be expected that a relatively large portion of the critically ill COVID-19 patients are (morbidly) obese. We could not identify any studies on the effect of obesity on chloroquine pharmacokinetics in the available literature. While the pharmacokinetic model by Zhao et al. [20] identified weight as a significant covariate for pharmacokinetic parameters using a fixed allometric approach in data from (presumably normal-weight) adults and children, there is no information about whether this model can be extrapolated to obese patients. Given the fact that the typical values for chloroquine clearance and volume of distribution are already very large $(59.1 \mathrm{~L} / \mathrm{h}$ and $2870 \mathrm{~L}$ for central and $1890 \mathrm{~L}$ for peripheral volume of distribution), it is unlikely that obesity significantly impacts the volume of distribution. For example, for propofol, which has similar pharmacokinetic properties to chloroquine with a very large volume of distribution, high clearance, and a prolonged terminal elimination half-life in normal-weight patients, no increase in the volume of distribution was found in obese patients [62]. Until more information becomes available, it can be assumed that the increase in clearance is not more than an increase with bodyweight to the power of 0.75 , which is similar to the increase reported when going from children to adults [20]. In Fig. 1, concentration-time profiles are given for a morbidly obese patient assuming this allometric increase in clearance, while the volumes of distribution were kept at values for an individual of $80 \mathrm{~kg}$. The results of this figure illustrate 
that in this worst-case scenario assuming increased clearance values in obese patients, somewhat lower concentrations are obtained in these patients for the standard-dose regimen that used fixed dosages. For the dosing algorithm of Pussard et al. [47], which we adapted for obese patients by capping the dose to a dose for a $80-\mathrm{kg}$ individual, chloroquine concentrations are comparable between morbidly obese and non-obese individuals with or without renal dysfunction (Fig. 1b). Alternatively, no increase in clearance in obese individuals can be anticipated, which would result in similar chloroquine concentrations as compared to the $70-\mathrm{kg}$ adult in Fig. 1, as the dose is capped at the dose for a $80-\mathrm{kg}$ individual. In between these scenarios, the results of a model in which clearance scales with lean body weight, which is also advocated by some as a better alternative to scaling with total body weight, can be found (data not shown) [63].

With regard to the influence of race, the pharmacokinetic properties of chloroquine do not differ in African subjects as compared to Caucasians [64]. However, in a population of Thai individuals, a two-fold lower clearance was observed [10] for which no real explanations could be found (see ESM). In the published model, also volume of distribution deviated from what was found in other publications. Perhaps some of these differences may be explained by differences in pharmacogenetic profiles in the Thai population compared with the Caucasian population with regard to CYP2D6 [65].

\section{Practical Implications and Safety Measures for Short-Term Use for COVID-19-Associated Pneumonia}

While there is currently no general advice on the optimal dose for chloroquine in SARS-CoV-2, it appears that with dosages proposed in malaria studies or in the 5-day treatment schedules currently used for COVID-19, variations in plasma concentrations as a result of obesity, renal dysfunction, or underweight may be limited (Fig. 1). As described in the previous section, this may also apply to critically ill patients. Regarding the influence of obesity, the concentration-time profile that can be expected assuming an increase in clearance in the obese population according to an 0.75 allometric scaling function, should be seen as a worst-case scenario compared to no increase or an increase with lean body weight (see Sect. 6). When renal dysfunction occurs in these obese patients, the effects of these two covariates may even compensate for each other. With respect to renal dysfunction in a $70-\mathrm{kg}$ individual, concentration-time profiles seem similar to that of a 50-kg individual when a fixed-dose regimen is given (Fig. 1a). As a result, also for renal dysfunction, no specific measures seem necessary. For children, there is ample information on the safety of loading doses from malaria studies that can be used as guidance, even though below the age of 6 months (Fig. 2) there is only very limited safety and dosing information. Given the available literature, children are extremely sensitive for overdose, and therefore misuse, dosing errors, or an accidental overdose may be fatal.

Less is known about what differences to expect regarding oral bioavailability. Even though in most reports, the oral bioavailability is between 70 and $90 \%$ [6, 7], slower or incomplete absorption could be expected, particularly in critically patients. In addition, absorption may be reduced when taken without food resulting in lower area under the curve and peak concentrations [8], which may reduce the chance on toxic peak concentrations, although it may also reduce the opportunity to reach an effective plasma concentration. Finally, magnesium-containing antacids could further lower the absorption of chloroquine [9].

With the dosages demonstrated in Fig. 1, plasma concentrations appear to increase no higher than 1.0 or 1.5 $\mu \mathrm{mol} / \mathrm{L}$ (Fig. 1), which is below the concentration of 2.5 $\mu \mathrm{mol} / \mathrm{L}$ that was associated with toxicity during long-term use for rheumatoid arthritis [37], recovery of a case after massive overdose [34], and reversible toxicity with intravenous dosing [7]. As information on efficacy against COVID19-associated pneumonia is not yet available, an important question is what toxicity would be acceptable. With the dosages proposed for malaria or COVID-19, expected toxicity is mainly related to QTc prolongation and widening of the QRS complex. Chloroquine cardiotoxicity seems specifically relevant for COVID-19, since an acute myocarditis was recently reported as a possible complication of COVID-19 [66]. Particularly in the case of co-treatment with other QTcprolonging agents such as amiodarone, macrolide antibiotics (such as azithromycin), ondansetron, and many others [67], before the start of chloroquine treatment an electrocardiogram should be performed and QTc time measured and repeated after the start of chloroquine treatment and other potentially QTc-prolonging agents on a daily basis. In addition, chloroquine could lead to hypoglycemia [9], for which additional monitoring needs to be considered. In those cases where toxicity would occur at therapeutic doses, we can learn from reports on chloroquine overdose, where it was shown that even after massive overdoses toxic effects beyond $24 \mathrm{~h}$ are rare [34], which may be explained by rapid redistribution to tissues despite the fact that the elimination half-life is about 2 weeks.

\section{Conclusions}

While promising announcements from in vitro studies and a preliminary clinical report may promote the use of chloroquine for SARS-CoV-2 infection, controlled clinical trials are still lacking. This also applies to hydroxychloroquine, 
which is referred to as less toxic than chloroquine and perhaps more effective against SARS-CoV-2 [1], with others reporting less in vitro activity [68]. The lack of reliable information on what concentrations to aim for or doses to use for COVID-19-associated pneumonia implies that for both adults and children doses should be considered that have been proven to be both effective and safe in malaria and that result in early high concentrations. In doses used for malaria, tolerability of these dosages is good provided QTc measurements before and after the start of treatment are performed, especially when chloroquine is given together with other drugs that can potentially prolong QTc or with cardiac involvement of COVID-19. Renal dysfunction or morbid obesity may introduce some variability even though their influence seems acceptable in relation to variability for instance resulting from underweight. Even though bioavailability is good, when given in critically ill patients, reduced absorption may be expected, particularly when enteral feeding is hampered because food may increase the absorption. However, clinical experience has shown that chloroquine has a very narrow margin of safety. The adult therapeutic dosage for malaria is $10 \mathrm{mg} / \mathrm{kg}$ whereas a single dose of $30 \mathrm{mg} /$ $\mathrm{kg}$ may be lethal. Finally, although infrequent, poisoning in children is extremely dangerous because children are particularly sensitive to chloroquine toxicity with one to two tablets being potentially fatal. With that in mind, it seems that if this drug is to be more widely used, its distribution must be strictly controlled and patients should be warned to keep the drugs out of reach from others, in particular (young) children.

\section{Compliance with Ethical Standards}

Conflict of interest Cornelis Smit, Mariska Y.M. Peeters, John N. van den Anker, and Catherijne A.J. Knibbe have no conflicts of interest that are directly relevant to the content of this article.

Funding No funding was received for the preparation of this article.

Data Availability The applied NONMEM control stream and R-code to create the datasets used for the simulations can be found in the ESM.

Open Access This article is licensed under a Creative Commons Attribution-NonCommercial 4.0 International License, which permits any non-commercial use, sharing, adaptation, distribution and reproduction in any medium or format, as long as you give appropriate credit to the original author(s) and the source, provide a link to the Creative Commons licence, and indicate if changes were made. The images or other third party material in this article are included in the article's Creative Commons licence, unless indicated otherwise in a credit line to the material. If material is not included in the article's Creative Commons licence and your intended use is not permitted by statutory regulation or exceeds the permitted use, you will need to obtain permission directly from the copyright holder.To view a copy of this licence, visit http://creativecommons.org/licenses/by-nc/4.0/.

\section{References}

1. Yao X, Ye F, Zhang M, Cui C, Huang B, Niu P, et al. In vitro antiviral activity and projection of optimized dosing design of hydroxychloroquine for the treatment of severe acute respiratory syndrome coronavirus 2 (SARS-CoV-2). Clin Infect Dis. 2020. https://doi.org/10.1093/cid/ciaa237.

2. Wang M, Cao R, Zhang L, Yang X, Liu J, Xu M, et al. Remdesivir and chloroquine effectively inhibit the recently emerged novel coronavirus (2019-nCoV) in vitro. Cell Res. 2020;30:269-71.

3. Gao J, Tian Z, Yang X. Breakthrough: chloroquine phosphate has shown apparent efficacy in treatment of COVID-19 associated pneumonia in clinical studies. Biosci Trends. 2020;14:72-3.

4. Vincent MJ, Bergeron E, Benjannet S, Erickson BR, Rollin PE, Ksiazek TG, et al. Chloroquine is a potent inhibitor of SARS coronavirus infection and spread. Virol J. 2005;2:69.

5. Touret F, de Lamballerie X. Of chloroquine and COVID-19. Antiviral Res. 2020;177:104762.

6. White NJ, Watt G, Bergqvist Y, Njelesani EK. Parenteral chloroquine for treating falciparum malaria. J Infect Dis. 1987;155:192-201.

7. Gustafsson LL, Walker O, Alván G, Beermann B, Estevez F, Gleisner L, et al. Disposition of chloroquine in man after single intravenous and oral doses. Br J Clin Pharmacol. 1983;15:471-9.

8. Tulpule A, Krishnaswamy K. Effect of food on bioavailability of chloroquine. Eur J Clin Pharmacol. 1982;23:271-3.

9. Alliance Pharmaceuticals. Summary of Product Characteristics: Avaclor. https://www.medicines.org.uk/emc/product/5490/smpc. Accessed 16 Apr 2020.

10. Höglund R, Moussavi Y, Ruengweerayut R, Cheomung A, Äbelö A, Na-Bangchang K. Population pharmacokinetics of a three-day chloroquine treatment in patients with Plasmodium vivax infection on the Thai-Myanmar border. Malar J. 2016;15:1-9.

11. Frisk-Holmberg M, Bergqvist Y, Termond E, Domeij-Nyberg B. The single dose kinetics of chloroquine and its major metabolite desethylchloroquine in healthy subjects. Eur J Clin Pharmacol. 1984;26:521-30.

12. Sahin S, Benet LZ. The operational multiple dosing half-life: a key to defining drug accumulation in patients and to designing extended release dosage forms. Pharm Res. 2008;25:2869-77.

13. Gustafsson L, Lindstrom B, Grahnen A, Alvan G. Chloroquine excretion following malaria prophylaxis. Br J Clin Pharmacol. 1987;24:221-4.

14. Ducharme J, Farinotti R. Clinical pharmacokinetics and metabolism of chloroquine: focus on recent advancements. Clin Pharmacokinet. 1996;31:257-74.

15. Adelusi SA, Salako LA. Kinetics of the distribution and elimination of chloroquine in the rat. Gen Pharmacol. 1982;13:433-7.

16. Gustafsson LL, Bergqvist Y, Ericsson O, Larsson M, Rombo L. Pitfalls in the measurement of chloroquine concentration. Lancet. 1983;1:126.

17. Berliner RW, Earle DP, Taggart JV, Zubrod CG, Welch WJ, Conan NJ, et al. Studies on the chemotherapy of the human malarias. VI. The physiological disposition, antimalarial activity, and toxicity of several derivatives of 4-aminoquinoline. J Clin Invest. 1948;27:98-107.

18. Daher A, Aljayyoussi G, Pereira D, Lacerda MVG, Alexandre MAA, Nascimento CT, et al. Pharmacokinetics/pharmacodynamics of chloroquine and artemisinin-based combination therapy with primaquine. Malar J. 2019;18:1-9.

19. Ursing J, Rombo L, Eksborg S, Larson L, Bruvoll A, Tarning J, et al. High-dose chloroquine for uncomplicated plasmodium falciparum malaria is well tolerated and causes similar QT interval prolongation as standard-dose chloroquine in children. Antimicrob Agents Chemother. 2020;64:1-12. 
20. Zhao Q, Tensfeldt TG, Chandra R, Mould DR. Population pharmacokinetics of azithromycin and chloroquine in healthy adults and paediatric malaria subjects following oral administration of fixed-dose azithromycin and chloroquine combination tablets. Malar J. 2014;13:1-8.

21. Bergqvist Y, Domeij-Nyberg B. Distribution of chloroquine and its metabolite desethyl-chloroquine in human blood cells and its implication for the quantitative determination of these compounds in serum and plasma. J Chromatogr. 1983;272:137-48.

22. Walker O, Birkett DJ, Alván G, Gustafsson LL, Sjöqvist F. Characterization of chloroquine plasma protein binding in man. $\mathrm{Br} \mathbf{J}$ Clin Pharmacol. 1983;15:375-7.

23. Gustafsson LL, Rombo L, Alván G, Björkman A, Lind M, Walker $\mathrm{O}$. On the question of dose-dependent chloroquine elimination of a single oral dose. Clin Pharmacol Ther. 1983;34:383-5.

24. Han Y, Pham HT, Xu H, Quan Y, Mesplède T. Antimalarial drugs and their metabolites are potent Zika virus inhibitors. J Med Virol. 2019;91:1182-90.

25. Essien EE, Ette EI. Effects of chloroquine and didesethylchloroquine on rabbit myocardium and mitochondria. J Pharm Pharmacol. 1986;38:543-6.

26. Kim K-A, Park J-Y, Lee J-S, Lim S. Cytochrome P450 2 C8 and CYP3A4/5 are involved in chloroquine metabolism in human liver microsomes. Arch Pharm Res. 2003;26:631-7.

27. Finielz P, Gendoo Z, Chuet C, Guiserix J. Interaction between cyclosporin and chloroquine. Nephron. 1993;65:333.

28. Nampoory MR, Nessim J, Gupta RK, Johny KV. Drug interaction of chloroquine with ciclosporin. Nephron. 1992;62:108-9.

29. Khan FY. Imported Plasmodium vivax malaria complicated by reversible myocarditis. J Family Community Med. 2019;26:232-4.

30. Frisk-Holmberg M, Bergqvist Y, Domeij-Nyberg B. Steady state disposition of chloroquine in patients with rheumatoid disease. Eur J Clin Pharmacol. 1983;24:837-9.

31. Brocks DR, Mehvar R. Stereoselectivity in the pharmacodynamics and pharmacokinetics of the chiral antimalarial drugs. Clin Pharmacokinet. 2003;42:1359-82.

32. Riou B, Barriot P, Rimailho A, Baud FJ. Treatment of severe chloroquine poisoning. N Engl J Med. 1988;318:1-6.

33. Britton WJ, Kevau IH. Intentional chloroquine overdosage. Med J Aust. 1978;2:407-10.

34. Stiff G, Robinson D, Cugnoni HL, Touquet R, Dalton AM. Massive chloroquine overdose: a survivor. Postgrad Med J. 1991;67:678-9.

35. Stead AH, Moffat AC. A collection of therapeutic, toxic and fatal blood drug concentrations in man. Hum Toxicol. 1983;2:437-64.

36. Jaeger A, Sauder P, Kopferschmitt J, Flesch F. Clinical features and management of poisoning due to antimalarial drugs. Med Toxicol Adverse Drug Exp. 1987;2:242-73.

37. Frisk-Holmberg M, Bergkvist Y, Domeij-Nyberg B, Hellström L, Jansson F. Chloroquine serum concentration and side effects: evidence for dose-dependent kinetics. Clin Pharmacol Ther. 1979;25:345-50.

38. Cann HM, Verhulst HL. Fatal acute chloroquine poisoning in children. Pediatrics. 1961;27:95-102.

39. Kelly JC, Wasserman GS, Bernard WD, Schultz C, Knapp J. Chloroquine poisoning in a child. Ann Emerg Med. 1990;19:47-50.

40. Collee GG, Samra GS, Hanson GC. Chloroquine poisoning: ventricular fibrillation following 'trivial' overdose in a child. Intensive Care Med. 1992;18:170-1.

41. Markowitz HA, Mcginley JM. Chloroquine poisoning in a child. JAMA. 1964;189:950-1.

42. Keyaerts E, Vijgen L, Maes P, Neyts J, Van Ranst M. In vitro inhibition of severe acute respiratory syndrome coronavirus by chloroquine. Biochem Biophys Res Commun. 2004;323:264-8.

43. Nix DE, Goodwin SD, Peloquin CA, Rotella DL, Schentag JJ. Antibiotic tissue penetration and its relevance: impact of tissue penetration on infection response. Antimicrob Agents Chemother. 1991;35:1953-9.

44. Müller M, dela Peña A, Derendorf H. Issues in pharmacokinetics and pharmacodynamics of anti-infective agents: distribution in tissue. Antimicrob Agents Chemother. 2004;48:1441-533.

45. Mouton JW, Theuretzbacher U, Craig WA, Tulkens PM, Derendorf H, Cars O. Tissue concentrations: do we ever learn? J Antimicrob Chemother. 2008;61:235-7.

46. Vallee E, Azoulay-Dupuis E, Pocidalo JJ, Bergogne-Berezin E. Activity and local delivery of azithromycin in a mouse model of Haemophilus influenzae lung infection. Antimicrob Agents Chemother. 1992;36:1412-7.

47. Pussard E, Lepers JP, Clavier F, Raharimalala L, Le Bras J, FriskHolmberg M, et al. Efficacy of a loading dose of oral chloroquine in a 36-hour treatment schedule for uncomplicated Plasmodium falciparum malaria. Antimicrob Agents Chemother. 1991;35:406-9.

48. Walker O, Dawodu A, Adeyokunnu A, Salako L, Alvan G. Plasma chloroquine and desethylchloroquine concentrations in children during and after chloroquine treatment for malaria. Br J Clin Pharmacol. 1983;16:701-5.

49. Salako LA, Walker O, Iyun AO. Pharmacokinetics of chloroquine in renal insufficiency. Afr J Med Med Sci. 2005;13:177-82.

50. Adelusi S, Dawodu A, Salako L. Kinetics of the uptake and elimination of chloroquine in children with malaria. Br J Clin Pharmacol. 1982;14:483-7.

51. Obua C, Hellgren U, Ntale M, Gustafsson LL, Ogwal-Okeng JW, Gordi T, et al. Population pharmacokinetics of chloroquine and sulfadoxine and treatment response in children with malaria: suggestions for an improved dose regimen. Br J Clin Pharmacol. 2008;65:493-501.

52. Edwards G, Looareesuwan S, Davies AJ, Wattanagoon Y, Phillips RE, Warrell DA. Pharmacokinetics of chloroquine in Thais: plasma and red-cell concentrations following an intravenous infusion to healthy subjects and patients with Plasmodium vivax malaria. Br J Clin Pharmacol. 1988;25:477-85.

53. Ursing J, Rombo L, Bergqvist Y, Rodrigues A, Kofoed P-E. Highdose chloroquine for treatment of chloroquine-resistant Plasmodium falciparum malaria. J Infect Dis. 2016;213:1315-21.

54. Akintonwa A, Odutola TA, Edeki T, Mabadeje AF. Hemodialysis clearance of chloroquine in uremic patients. Ther Drug Monit. 1986;8:285-7.

55. Roberts DJ, Hall RI. Drug absorption, distribution, metabolism and excretion considerations in critically ill adults. Expert Opin Drug Metab Toxicol. 2013;9:1067-84.

56. Vet NJ, Brussee JM, De Hoog M, Mooij MG, Verlaat CWM, Jerchel IS, et al. Inflammation and organ failure severely affect midazolam clearance in critically ill children. Am J Respir Crit Care Med. 2016;194:58-66.

57. Clark IA, Budd AC, Alleva LM, Cowden WB. Human malarial disease: a consequence of inflammatory cytokine release. Malar J. 2006;5:1-32.

58. Smit C, De Hoogd S, Brüggemann RJM, Knibbe CAJ. Obesity and drug pharmacology: a review of the influence of obesity on pharmacokinetic and pharmacodynamic parameters. Expert Opin Drug Metab Toxicol. 2018;14:275-85.

59. Knibbe CAJ, Brill MJE, Van Rongen A, Diepstraten J, van der Graaf PH, Danhof M. Drug disposition in obesity: toward evidence-based dosing. Annu Rev Pharmacol Toxicol. 2015;55:149-67.

60. Wu C, Chen X, Cai Y, Xia J, Zhou X, Xu S, et al. Risk factors associated with acute respiratory distress syndrome and death in patients with coronavirus disease 2019 pneumonia in Wuhan, China. JAMA Intern Med. 2020. https://doi.org/10.1001/jamai nternmed.2020.0994. 
61. Moser JAS, Galindo-Fraga A, Ortiz-Hernández AA, Gu W, Hunsberger S, Galán-Herrera J-F, et al. Underweight, overweight, and obesity as independent risk factors for hospitalization in adults and children from influenza and other respiratory viruses. Influenza Other Respir Viruses. 2019;13:3-9.

62. Van Kralingen S, Diepstraten J, Peeters MYM, Deneer VHM, van Ramshorst B, Wiezer RJ, et al. Population pharmacokinetics and pharmacodynamics of propofol in morbidly obese patients. Clin Pharmacokinet. 2011;50:739-50.

63. McLeay S, Morrish G, Kirkpatrick C, Green B. The relationship between drug clearance and body size: systematic review and meta-analysis of the literature published from 2000 to 2007. Clin Pharmacokinet. 2012;51:319-30.

64. Walker O, Salako LA, Alván G, Ericsson O, Sjöqvist F. The disposition of chloroquine in healthy Nigerians after single intravenous and oral doses. Br J Clin Pharmacol. 1987;23:295-301.

65. Charoenchokthavee W, Panomvana D, Sriuranpong V, Areepium N. Prevalence of CYP2D6*2, CYP2D6*4, CYP2D6*10, and
CYP3A5*3 in Thai breast cancer patients undergoing tamoxifen treatment. Breast Cancer. 2016;8:149-55.

66. Inciardi RM, Lupi L, Zaccone G, Italia L, Raffo M, Tomasoni D, et al. Cardiac involvement in a patient with coronavirus disease 2019 (COVID-19). JAMA Cardiol. 2020. https://doi.org/10.1001/ jamacardio.2020.1096.

67. Woosley R, Heise C, Gallo T, Tate J, Woosley D, Romero K. QTdrugs list. https://www.CredibleMeds.org. [Accessed $30 \mathrm{Mar}$ 2020].

68. Liu J, Cao R, Xu M, Wang X, Zhang H, Hu H, et al. Hydroxychloroquine, a less toxic derivative of chloroquine, is effective in inhibiting SARS-CoV-2 infection in vitro. Cell Discov. 2020;6:16.

69. Dutch Working Party on Antibiotic Policy (Stichting Werkgroep Antibiotica Beleid, SWAB). Medicamenteuze behandelopties bij patiënten met COVID-19 (infecties met SARS-CoV-2). https:// swab.nl/nl/covid-19. Accessed 24 Mar 2020. 